\title{
(Q) Instrumento
}

ISSN 1984-5499

Licenciado sob uma Licença Creative Commons

\section{O trabalho docente na versão preliminar do Projeto Pedagógico Institucional para os cursos de licenciaturas da UFJF}

\author{
The teaching work in the preliminary version of the Institutional Pedagogical Project for \\ UFJF undergraduate courses
}
El trabajo docente en la versión preliminar del Proyecto Pedagógico Institucional para los cursos de licenciaturas de la UFJF

\author{
Andreia Rezende Garcia-Reis ${ }^{1}$, Andressa Barcellos Correia da Silva ${ }^{2}$ \\ Universidade Federal de Juiz de Fora, Juiz de Fora/MG, Brasil
}

Recebido em: 19/11/2018

Aceito em: 30/04/2019

\section{Resumo}

Este estudo visa investigar a compreensão do trabalho docente e o estatuto do professor formado pela Universidade Federal de Juiz de Fora, em seus diversos cursos de formação para a docência, por meio da análise da versão preliminar do Projeto Pedagógico Institucional para os cursos de licenciatura - PPI (UNIVERSIDADE FEDERAL DE JUIZ DE FORA, 2018). Adota-se como aporte teórico o Interacionismo Sociodiscursivo, em sua corrente de análise de textos prescritivos do trabalho docente. Considera-se que as significações em torno da profissão e do trabalho docente são construídas também pelos textos que tratam dessa atividade, por isso precisam ser estudados e compreendidos. A pesquisa revela a significação do trabalho docente como atividade profissional, intencional e metódica, para a qual é exigida formação específica e contextualizada.

Palavras-chave: Trabalho docente. Formação de professores. Projeto Pedagógico Institucional das Licenciaturas.

\begin{abstract}
The purpose of this study is to investigate the understanding of the teaching work and the Teacher's Regulations created by the Federal University of Juiz de Fora in its various teaching-driven educational courses through the analysis of the preliminary version of the Institutional Pedagogical Project for undergraduate courses - PPI (UFJF, 2018). The Socio-Discursive Interactionism (BRONCKART, 2006), in its stream of analyses of prescriptive texts of the teaching work (MACHADO, 2009), is adopted as a theoretical basis. The meanings (BRONCKART, 2015) for the teaching profession and work are considered to be constructed also by the texts that approach this activity, so they need to be studied and understood. The investigation reveals the significance of the teaching work as a professional, intentional and methodical activity, for which specific and contextualized training is required.
\end{abstract}

Keywords: Teaching work. Teacher education. Undergraduate Institutional Pedagogical Project.

\footnotetext{
${ }^{1}$ E-mail: andreiargarcia@yahoo.com.br

2 E-mail: dessa barcellos@hotmail.com
} 


\section{Resumen}

Este estudio pretende investigar la comprensión del trabajo docente y el estatuto del profesor formado por la Universidad Federal de Juiz de Fora, en sus diversos cursos de formación para la docencia, a través del análisis de la versión preliminar del Proyecto Pedagógico Institucional para los cursos de licenciatura - PPI (UNIVERSIDAD FEDERAL DE JUEZ DE FUERA, 2018). Se adopta como aporte teórico el Interaccionismo Sociodiscursivo, en su corriente de análisis de textos prescriptivos del trabajo docente. Se considera que las significaciones en torno a la profesión y del trabajo docente se construyen también por los textos que tratan de esa actividad, por lo que necesitan ser estudiados y comprendidos. La investigación revela la significación del trabajo docente como actividad profesional, intencional y metódica, para la cual se requiere formación específica y contextualizada.

Palabras clave: Trabajo docente. Formación de profesores. Proyecto Pedagógico Institucional de las Licenciaturas.

\section{Introdução}

Nos últimos anos, novos documentos que orientam a educação básica brasileira foram publicados, principalmente no fim do século XX e início do século XXI (BRASIL, 1997; 1998; BRASIL, 2017), e, com isso, pode-se afirmar que o ensino no Brasil passou e vem passando por várias transformações. As mudanças na escola básica afetaram a formação de professores e, consequentemente, novos documentos para as licenciaturas também foram produzidos, como as Diretrizes Curriculares Nacionais para a Formação de Professores da Educação Básica, em 2002, e as Diretrizes Curriculares Nacionais para a Formação Inicial e Continuada dos Profissionais do Magistério da Educação Básica, em 2015.

Ao pesquisar sobre os diversos cursos de licenciaturas e refletir sobre suas configurações, Gatti (2013) acredita que a formação inicial de professores é crucial na nossa sociedade. No entanto, a autora percebe que essa formação vem sofrendo uma crise no cenário atual, pois o professor, que trabalha com a formação do humano, tem que considerar um cenário com as novas demandas sociais e isso gera muitas tensões. O panorama atual dessa formação, ainda conforme Gatti (2013), possui currículos fragmentados, com conteúdos genéricos e com grande dissociação entre teoria e prática, estágios fictícios e avaliação precária.

Em pesquisa recente, Garcia-Reis e Silva (2018) fizeram uma análise do Projeto Pedagógico do Curso (PPC) de Letras da Universidade Federal de Juiz de Fora e os resultados vão ao encontro das pesquisas de Gatti (2010, 2013). Não fica explícito, nas ementas e referências bibliográficas do PPC do curso, como ele formará um profissional que desenvolva capacidades linguísticas para o uso e para o ensino da língua materna, o que revela uma formação fragilizada nesse aspecto.

Em uma tentativa de superar ou até mesmo minimizar a crise citada por Gatti (2013), recentemente, mais precisamente em 2015, houve uma renovação do texto que orienta a formação 
inicial de professores com a publicação das Diretrizes Curriculares Nacionais para a formação em nível superior (cursos de licenciatura, cursos de formação pedagógica para graduados e cursos de segunda licenciatura) e para a formação continuada (BRASIL, 2015b).

Com a publicação das Diretrizes em 2015, as instituições de educação superior que ofertam cursos de formação de professores devem articular o ensino, a pesquisa e a extensão no interior das práticas formativas. Além disso, é evidenciado que o Projeto Pedagógico de Curso (PPC), em articulação com o Projeto Pedagógico Institucional (PPI) e o Projeto de Desenvolvimento Institucional (PDI), deve abranger diferentes características e dimensões de iniciação à docência. Com isso, fica definido que cada instituição formadora de professores deve, obrigatoriamente, ter um PPI e diferentes PPCs alinhados às Diretrizes.

A partir da demanda das Diretrizes de 2015 e da necessidade institucional de rever a configuração dos diferentes cursos de licenciatura da instituição, surge o Projeto Institucional das Licenciaturas da Universidade Federal de Juiz de Fora, cuja versão preliminar foi apresentada à comunidade acadêmica em meados de $2018^{1}$. Tal documento estabelece condições institucionais para a construção e valorização dos cursos de licenciatura e ainda define princípios, fundamentos e procedimentos a serem observados nas políticas, na gestão e nos programas e cursos de formação para a docência na Educação Básica da UFJF (UNIVERSIDADE FEDERAL DE JUIZ DE FORA, 2018).

A pesquisa apresentada neste artigo analisa a versão preliminar do PPI da UFJF e se insere no campo teórico-metodológico do Interacionismo Sociodiscursivo (BRONCKART, 2006), o qual será mais explorado a seguir. Além disso, está ligada ao grupo de pesquisa Interação, Sociedade e Educação (CNPq/UFJF) e estabelece um diálogo e mesmo uma continuidade às pesquisas anteriores do grupo, algumas delas relatadas em Garcia-Reis (2017) e em Garcia-Reis e Silva (2018).

A partir da análise do documento do PPI na perspectiva do Interacionismo Sociodiscursivo (ISD), fundamentada na escola brasileira do ISD (DOLZ, 2009; PEREIRA; MEDRADO; REICHMANN, 2015) e nas pesquisas sobre o trabalho docente (MACHADO, 2004; BRONCKART, 2006), este artigo busca responder às seguintes questões de investigação: a) há uma compreensão de trabalho docente no PPI?; b) qual é a compreensão desse trabalho? c) qual é o estatuto do professor formado pela UFJF presente no PPI?

Para responder a tais questões, apresentaremos, a seguir, os aportes teóricos que temos assumido em nossas pesquisas, para, em seguida, discutirmos a trajetória de análise e a própria análise do documento em estudo, e, por fim, tecermos as considerações finais. 


\section{Aportes teóricos}

Esta pesquisa se insere no campo teórico-metodológico do Interacionismo Sociodiscursivo (ISD) (BRONCKART, 2006), conforme mencionado anteriormente, o qual assume uma abordagem transdisciplinar, pois busca contribuições na Filosofia, na Sociologia, na Psicologia e na Linguística para a condução de suas pesquisas e o avanço da própria teoria. Com isso, é possível afirmar que não se trata de uma corrente linguística nem psicológica ou sociológica, como admite Bronckart (2006), trata-se de uma corrente da ciência do humano.

O ISD pode ser considerado como um prolongamento do interacionismo social de Vygotsky, mas a característica que o distingue é a ênfase especial dada ao papel da linguagem no desenvolvimento psíquico humano (MACHADO; LOUSADA, 2012). Jean-Paul Bronckart, seu principal fundador, assume que a linguagem desempenha um papel central no funcionamento psíquico e no desenvolvimento do psiquismo humano, bem como nas atividades e ações, pois é ela que organiza e regula tanto as interações quanto as atividades. Portanto, a especificidade do ISD é a de postular que "o problema da linguagem é absolutamente central ou decisivo para essa ciência do humano" (BRONCKART, 2006, p. 10).

Assim como a linguagem, a análise das ações efetivas, ou seja, o exame de situações concretas e das características que circundam essas situações, é também objetivo dos estudos do ISD (BRONCKART, 2005). Nesse sentido, a análise tanto do agir verbal quanto do não verbal de adultos em situações de trabalho (no nosso caso específico, o trabalho de ensino) tem sido uma das contribuições trazidas pelas pesquisas do ISD ao buscarmos compreender as ações dos trabalhadores da educação e o desenvolvimento de uma consciência sobre a sua prática, por meio de atitudes reflexivas sobre ela e sobre o desenvolvimento desse trabalho, com o auxílio de metodologias apropriadas que garantem o rigor desses estudos.

Para o ISD, é fundamental discutir a importância do trabalho para o desenvolvimento tanto da espécie quanto do indivíduo. Com isso, Bronckart (2006) define claramente que o trabalho se constitui como um tipo de atividade ou de prática, mais precisamente, como um tipo de atividade própria da espécie humana.

Porém, o termo "trabalho", até o século XIX, designava as atividades que produziam bens materiais. Foi só a partir das ideias de Engels e de Marx que esse termo adquiriu um ponto de vista universal e atemporal, considerando também o trabalho intelectual. Portanto, em conformidade com 
esses autores, o trabalho seria a:

[...] condição básica e fundamental de qualquer vida humana, fundadora do humano e do social, como atividade universal e criativa, de expressão e realização do ser humano [...] o "verdadeiro trabalho" seria aquele que engaja a totalidade do humano e potencializa o desenvolvimento de suas capacidades [...] (MACHADO, 2007, p. 84).

No entanto, foi só mais recentemente, a partir do final da década de 1990, que o trabalho do professor passou a ser considerado como um "verdadeiro trabalho" e tornou-se objeto de pesquisas. Em muitas situações anteriores, e até mesmo nos dias atuais, o trabalho de ensino é considerado um dom, uma atividade familiar, fraternal e que, por isso, não se faz necessária uma aprendizagem sistemática e uma formação específica para a atuação profissional. Esse cenário evidencia a ausência de profissionalização algumas vezes defendida por aqueles que consideram a formação para a atividade docente desnecessária.

Atualmente, após muitas pesquisas e contribuições trazidas pelos estudos da Psicologia (CLOT, 2006) e da Linguística Aplicada (MACHADO, 2004), já se sabe que o trabalho docente mobiliza o ser integral do professor "em suas diferentes dimensões, com o objetivo de criar um meio propício à aprendizagem de determinados conteúdos e ao desenvolvimento de determinadas capacidades dos alunos" (MACHADO; BRONCKART, 2009. p. 40).

Compreender o papel da linguagem no agir humano nos leva à análise dos textos e discursos que são produzidos sobre as diversas situações de trabalho. Estudar o trabalho na perspectiva do ISD é estudar os textos que dizem sobre esse trabalho, pois, para que possamos compreender melhor a atividade educacional, os objetos de análise são os textos que se desenvolvem tanto na própria situação de trabalho quanto os que se desenvolvem sobre essa atividade profissional.

Um desses textos são aqueles denominados textos prescritivos, aqueles que dizem sobre o trabalho docente e têm como finalidade estabelecer as tarefas, os objetivos, as condições materiais, o desenvolvimento temporal, os resultados que delas são esperados, predefinindo as responsabilidades dos agentes envolvidos. Portanto, prefiguram as ações do trabalhador (MACHADO, 2009), descrevendo as regras e os procedimentos a serem adotados.

A análise dos textos prescritivos produzidos em diferentes situações faz com que possamos chegar a "conclusões mais sólidas sobre a rede discursiva que se desenvolve em torno do trabalho docente" (MACHADO; BRONCKART, 2009, p. 69). Ou seja, os textos prescritivos contribuem para construir as significações (BRONCKART, 2006; 2015) dessa atividade profissional; assim, estudá-los e 
pesquisá-los poderá contribuir para a clarificação das concepções sobre o estatuto do trabalho do professor e sobre o papel que lhe é atribuído.

Também é importante ressaltar que, como apontam Machado e Abreu-Tardelli (2009), esses textos que prescrevem o trabalho podem veicular aos professores uma responsabilização de sucesso ou de fracasso das atividades, o que pode gerar uma série de consequências, como estresse, fadiga, desvalorização do trabalho, entre outras.

O texto analisado neste artigo - o Projeto Pedagógico Institucional - pode ser compreendido como um texto prescritivo do trabalho docente, uma vez que regulamenta as ações formativas dos cursos de licenciatura da Universidade Federal de Juiz de Fora e tem caráter orientador e regulador dos projetos pedagógicos dos cursos de licenciatura a serem elaborados a partir de sua aprovação. O PPI é um texto que diz sobre o trabalho docente na perspectiva da formação de professores e isso também se faz importante, pois, como afirma Gatti (2013), os valores socialmente atribuídos à profissão docente estão associados àqueles atribuídos à sua formação, atribuição explicitada em documentos dessa natureza.

Na seção seguinte, revelamos a trajetória de análise deste documento e algumas de suas características, como um gênero textual prescritivo de uma atividade educacional.

\section{Trajetória da análise}

Este texto investiga a concepção de trabalho docente proposta no PPI e, ao adotar a rede conceitual do ISD, seguimos os seguintes passos:

1) Leitura do documento.

2) Pesquisa dos termos "trabalho, professor, docente, profissional do magistério e docência".

3) Avaliação das estruturas frasais que continham os termos pesquisados e análise dessas estruturas.

4) Releitura do documento para análise mais detida.

O documento estudado é uma versão preliminar do PPI, construído e elaborado por uma comissão de professores formadores de diferentes áreas do conhecimento e pertencentes a diferentes cursos de licenciatura da Universidade Federal de Juiz de Fora, a saber: um representante da área da Linguagem, um das Ciências Exatas, um das Ciências Humanas, um das Ciências Biológicas e Saúde, um 
representante da Faculdade de Educação, por meio da Coordenação de Disciplinas Pedagógicas das Licenciaturas, e a presidente do Fórum das Licenciaturas da UFJF e coordenadora dos cursos de licenciaturas da instituição².

Os membros da comissão foram eleitos em reunião do Fórum das Licenciaturas que, além de promoverem as discussões no coletivo de suas respectivas áreas e institutos, também conduziram as reuniões do Fórum nas quais o texto foi sendo apresentado, debatido e co-construído, a partir de solicitações de mudanças e acréscimos, que foram objeto de discussão e votação dos presentes em diferentes momentos. A versão objeto de análise neste texto é ainda uma versão preliminar, datada de maio de 2018, uma vez que o documento não foi aprovado em sua integralidade, embora tenha sido aprovada grande parte de seu conteúdo.

Em abril de 2018, em uma das reuniões do Fórum das Licenciaturas, cuja principal pauta era a discussão de trechos do PPI, as autoras deste artigo, juntamente com outros estudantes da licenciatura em Letras e em Pedagogia e estudantes da pós-graduação em Educação que compõem o grupo de pesquisa Interação, Sociedade e Educação (CNPq/UFJF), estiveram presentes, podendo acompanhar o debate em torno da configuração dos estágios e da escolha do estudante pela licenciatura em detrimento do bacharelado. Como já prevíamos, as discussões foram bastante acaloradas e marcadas pelas tensões próprias da formação de professores, como o Parecer das Diretrizes de 2015 menciona (BRASIL, 2015a).

\section{Análise do PPI}

As Diretrizes de 2015 demandam que as instituições de ensino superior elaborem uma proposta de formação de professores, pois há uma necessidade de valorização do professor e, consequentemente, da sua formação (BRASIL, 2015b). Como Bronckart (2006) aponta, o trabalho do professor ainda é uma atividade de difícil descrição, caracterização e de relativa opacidade, por isso acreditamos que a formação deve contemplar os diferentes elementos da atuação desse profissional.

Motivada pela aprovação das Resoluções CNE/CP no 1 e no 2, de 2002, iniciou-se, na UFJF, em 2003, uma discussão acerca de possibilidades institucionais de reformulação dos cursos de formação de professores. No início de 2004, essa discussão continuou com a presença de coordenadores de todas as licenciaturas, representantes do Colégio de Aplicação João XXIII e discentes. Desde então, a UFJF se propõe a pensar em configurações para os cursos de formação de professores, os quais vêm sendo alvo 
de muitas críticas (GATTI; NUNES, 2009; GATTI, 2010; GARCIA-REIS, 2017).

Porém, frente à aprovação, em 2015, das Diretrizes Curriculares Nacionais para a formação em nível superior (cursos de licenciatura, cursos de formação pedagógica para graduados e cursos de segunda licenciatura) e para a formação continuada (BRASIL, 2015b), constatou-se que todo o processo de reformulação não se concretizou da mesma forma em todas as licenciaturas. Dessa forma, a partir do Fórum de Licenciaturas, foi montada uma comissão para estudar a nova resolução e elaborar o PPI.

Com a retomada das reuniões do Fórum das Licenciaturas, teve início a construção de uma proposta de formação docente institucional, em busca do enfrentamento dos problemas detectados após muitos estudos e análises da situação dos cursos de licenciaturas da UFJF. A partir de então, uma comissão de professores formadores foi eleita, à qual se atribuiu a responsabilidade de consolidar um esboço de Projeto Político Institucional para a UFJF. Podemos afirmar que esse movimento está construindo democraticamente tal documento, pois conta com diferentes vozes e representações.

A consolidação de uma rede discursiva em torno da formação e do trabalho docente (MACHADO, 2009), em que o PPI se insere, revela-se importante a partir do momento em que os diversos textos trazem as significações (BRONCKART, 2006) construídas sobre a docência. Consideramos que pesquisar essas significações é relevante no contexto educacional brasileiro para verificarmos elementos coincidentes e/ou conflitantes que podem contribuir para o aperfeiçoamento das práticas formativas e da docência praticada nas instituições de ensino. Assim, acreditamos que os textos produzidos sobre a formação e o trabalho docente não inauguram por completo um novo modo de compreender essas duas formas de agir, pelo contrário, dialogam com outros já anteriormente elaborados e com eles estabelecem uma relação intertextual.

No caso específico do PPI (UNIVERSIDADE FEDERAL DE JUIZ DE FORA, 2018), o principal elo intertextual é com as Diretrizes Curriculares de Formação de Professores (BRASIL, 2015b), uma vez que são nelas que o documento em estudo fundamenta-se, ampara-se e revela sua importância e obrigatoriedade. Nos excertos a seguir, podemos confirmar essa intertextualidade:

CONSIDERANDO o currículo como o conjunto de valores propício à produção e à socialização de significados no espaço social e que contribui para a construção da identidade sociocultural do educando, dos direitos e deveres do cidadão, do respeito ao bem comum e à democracia, às práticas educativas formais e não formais e à orientação para o trabalho (BRASIL, 2015b, p. 2).

Currículo como o conjunto de valores propício à produção e à socialização de significados no espaço social e que contribui para a construção da identidade 
sociocultural da/do educanda/o, dos direitos e deveres da cidadã e do cidadão, do respeito ao bem comum e à democracia, às práticas educativas formais e não formais e à orientação para o trabalho (UNIVERSIDADE FEDERAL DE JUIZ DE FORA, 2018, p. 5).

Nos excertos acima, é possível notar que a concepção de currículo entre os dois documentos é exatamente a mesma, o que evidencia uma das faces da intertextualidade entre eles. Ainda, outro ponto em que há bastante proximidade entre eles é a compreensão do egresso de um curso de licenciatura, como vemos nos trechos:

\begin{abstract}
A/o Licenciada/o formada/o pela UFJF atuante como docente ou outro/a profissional da Educação Básica deve possuir um conjunto de saberes que a/o qualificam para exercer a docência neste nível, quer no âmbito do ensino, da gestão educacional e da coordenação pedagógica e dos processos de produção e difusão do conhecimento. Tais saberes são constituídos por conhecimentos teórico-conceituais (gerais, específicos e pedagógicos) e por habilidades práticas, articulados entre si, que the possibilitem propor, desenvolver e avaliar suas ações, de forma intencional e metódica e em cooperação com o coletivo escolar (UNIVERSIDADE FEDERAL DE JUIZ DE FORA, 2018, p. 39).

O(A) egresso(a) da formação inicial e continuada deverá possuir um repertório de informações e habilidades composto pela pluralidade de conhecimentos teóricos e práticos, resultado do projeto pedagógico e do percurso formativo vivenciado cuja consolidação virá do seu exercício profissional, fundamentado em princípios de interdisciplinaridade, contextualização, democratização, pertinência e relevância social, ética e sensibilidade afetiva e estética (BRASIL, 2015b, p. 7)
\end{abstract}

Já nesses últimos dois trechos, embora percebamos diferenças na redação, a compreensão do perfil do egresso como um profissional que atenda às demandas contextuais, democráticas, sociais, afetivas e estéticas (BRASIL, 2015b) está relacionada àquele que desenvolverá saberes e habilidades próprios à atuação docente em diferentes atividades profissionais (UFJF, 2018).

Ainda que um texto prescritivo como o PPI (UFJF, 2018) tenha caráter preferencialmente orientador e regulador das ações de formação nos cursos de licenciatura, em alguns trechos do documento parece haver um ocultamento da prescrição em favor de uma argumentação, às vezes modalizada, em defesa da formação para a docência e da importância de valorização dessa profissão e da necessidade da compreensão da docência como um campo profissional que exige formação especializada, como qualquer outro. Ao nos perguntarmos por que isso acontece, podemos supor, primeiramente, que é devido à compreensão de docência como atividade sacerdotal e maternal, para a qual basta o dom e a vocação, compreensão da qual discordamos e a qual criticamos. Além disso, supomos também que a argumentação em favor da profissionalização docente se deva pelo campo de 
disputa no qual se insere a formação de professores no Brasil (BRASIL, 2015a). Haveria a necessidade de primeiro convencer os leitores - são interlocutores imediatos os professores da carreira docente em nível superior, sobretudo os professores e coordenadores dos cursos de licenciatura da UFJF que compõem os Núcleos Docentes Estruturantes, responsáveis pela elaboração dos Projetos Pedagógicos dos cursos, sobre os quais o PPI estabelece interlocução direta - a avaliarem a configuração do curso de licenciatura do qual fazem parte e a produzirem modificações que atendam às demandas institucionais propostas no PPI e nas Diretrizes de 2015.

Pode-se dizer que isso ocorre quando é explicado que os currículos das Licenciaturas na UFJF devem ser organizados a partir de três núcleos formativos ${ }^{3}$ e, com isso, o documento reconhece que:

[...] tais disciplinas se constituirão no reconhecimento e valorização de uma epistemologia propriamente escolar que implica na produção de conhecimentos singulares e complexos. Isso significa o reconhecimento que as instituições e espaços educativos, campo de trabalho do/a futuro/a docente, como trabalhador/a da Educação na Escola Básica, mobilizam conhecimentos próprios que, apesar de terem íntima relação com os conhecimentos científicos, não podem ser traduzidos e reduzidos termo a termo àqueles produzidos no âmbito das ciências. Assim, neste PPI, assegura-se a autonomia dos cursos em definirem as nomenclaturas que irão caracterizar esse conjunto de disciplinas (UNIVERSIDADE FEDERAL DE JUIZ DE FORA, 2018, p. 45).

O trecho acima mostra que o documento argumenta em favor de um ponto de vista e o explicita ao leitor: o de que, embora haja o reconhecimento do valor das disciplinas teóricas e específicas de uma determinada área do conhecimento, há também que se enfatizar e destinar carga horária à formação para a docência, para a atuação em espaços educativos e escolares dos trabalhadores da educação básica. Como dissemos, esse trecho abandona o caráter prescritivo e opta pela argumentação, estratégia discursiva mais adequada para o alcance dos objetivos interacionais do documento, sobretudo se considerarmos tal trecho na sequência textual do PPI como um todo.

Em trechos como o anterior, notamos uma impessoalização na voz enunciativa do documento, revelando seu caráter institucional, ou seja, os sujeitos envolvidos na elaboração do texto estão ali na perspectiva institucional e, por isso, o caráter prescritivo é em seguida retomado. Mais uma vez, tal fato também ocorre com as Diretrizes de 2015, demonstrando mais uma vez a intertextualidade entre as prescrições aqui discutidas.

Em relação aos aspectos mais internos do PPI que optamos analisar neste estudo, podemos afirmar que há uma compreensão clara do trabalho docente no documento, pois muitas vezes aparece no texto o termo "trabalho docente". Em outros momentos, é feita menção à docência como profissão, 
por exemplo, na parte referente ao princípio norteador do PPI: "A docência como atividade profissional intencional e metódica" (UNIVERSIDADE FEDERAL DE JUIZ DE FORA, 2018, p. 29). Tal afirmação vai ao encontro do que aponta Nóvoa (2017), ao defender que, para ser professor, deve-se aprender a profissão e, para isso, exige-se um trabalho metódico e sistemático.

Consideramos que o aparecimento desse termo no texto é muito relevante, pois é o reconhecimento de que o ensino é um verdadeiro trabalho. Tal discurso nos mostra que, como afirma Bronckart (2009), o ensino não é um sacerdócio, os professores não são "iluminados", dotados de um "dom". Ao contrário, são trabalhadores que devem aprender seu métier e também adquirir experiência sobre ele e, dessa forma, serem considerados profissionais.

Além de reconhecer a docência como trabalho, o PPI compreende as ações que perpassam essa profissão:

No exercício da docência, a ação do/a profissional do magistério da Educação Básica é permeada por dimensões técnicas, políticas, éticas e estéticas por meio de sólida formação, envolvendo o domínio e manejo de conteúdos e metodologias, diversas linguagens, tecnologias e inovações, contribuindo para ampliar a visão e a atuação desse profissional (UNIVERSIDADE FEDERAL DE JUIZ DE FORA, 2018, p. 29).

O fato de reconhecer e admitir que o trabalho do professor não é simplesmente "dar aula" é muito importante para a valorização docente, sobretudo quando presente em um documento que regulamentará as escolhas curriculares dos cursos de licenciatura. Ao assumir a docência como uma atividade permeada por diferentes dimensões e saberes, notamos a defesa de um profissional cuja formação deverá ser diversa e, ao mesmo tempo, especializada em tais dimensões e saberes. Na busca de valorização e especialização da profissão docente, as Diretrizes de 2015 também assumem o caráter profissionalizante dessa atividade.

Outro aspecto a ser ressaltado é o estatuto do professor no documento estudado, ou seja, em que configurações o professor apresenta-se no PPI. Cabe destacar que fizemos uma separação entre o professor formador e o professor da Educação Básica, pois percebemos que eles surgem de formas diferentes no documento.

Segundo o PPI, o trabalho do professor da Educação Básica é permeado por diversas ações e, por isso, ele deve possuir um conjunto de saberes e ainda deve ser apto a ser ator do processo de ensino e de aprendizagem. Com isso, ele deve ser formado para ser um "sujeito criativo, propositivo, solidário e sensível às causas sociais identificadas com a construção de uma sociedade socialmente justa, 
democrática e inclusiva" (UNIVERSIDADE FEDERAL DE JUIZ DE FORA, 2018, p. 65).

Já o professor formador é a pessoa que deve, juntamente com outros membros da UFJF, participar do processo de organização, funcionamento e avaliação dos cursos. Além disso, é o ator envolvido na formação de professores e também o orientador do estágio, o qual deve acompanhar o discente nesse processo. Entretanto, há pouca menção ao trabalho do professor formador, que é, como o próprio documento afirma, ator do processo de formação. Contudo, conforme Machado (2009), é preciso considerar a atividade de formar docentes também como um trabalho e, por isso, acreditamos que se faz muito necessário valorizar e reconhecer e, como afirma Gatti (2013), ressituar o trabalho e o papel dos professores formadores.

Admitimos, assim como Gatti (2013), que os currículos das licenciaturas devem sofrer mudanças nas suas estruturas formativas. A formação inicial precisa propiciar ao futuro professor experiências e problematizações que levem a aprendizagens para "exercer uma prática educativa contextualizada, atenta às especificidades do momento, à cultura local e ao alunado diverso em sua trajetória de vida e expectativas escolares" (GATTI, 2013, p. 53).

Com isso, consideramos que o Projeto Pedagógico Institucional das Licenciaturas da Universidade Federal de Juiz de Fora é um documento de resistência frente aos ataques à Educação nos últimos anos e também de extrema importância, uma vez que ele propõe uma formação de professores mais integrada e cuja valorização deve se refletir nas propostas curriculares e nas diferentes ações dos cursos. Nesse sentido, concordamos com Nóvoa, ao considerarmos que a formação e o trabalho docente são duas atividades que precisam dialogar e se conhecer cotidianamente, pois "não pode haver uma boa formação de professores se a profissão estiver fragilizada, enfraquecida. Mas também não pode haver uma profissão forte se a formação de professores for desvalorizada e reduzida [...]" (NÓVOA, 2017, p. 131).

\section{Considerações finais}

Este texto buscou investigar a versão preliminar do Projeto Pedagógico Institucional das Licenciaturas da Universidade Federal de Juiz de Fora, publicizada no primeiro semestre de 2018, na busca de compreender as significações do trabalho docente e o estatuto do professor presentes no documento. Tal estudo se faz pertinente por se tratar de um documento prescritivo de extrema relevância na defesa e na consolidação da profissão docente como o exercício contextualizado de ações 
atorais e especializadas, no planejamento, condução, avaliação e gestão de processos de ensino.

A compreensão do trabalho docente no documento em análise é a de uma atuação profissional que envolve aspectos sociais, éticos, políticos e estéticos, além de capacidades e saberes específicos do campo do conhecimento em questão. No desenvolvimento desse trabalho, o profissional da docência é aquele que propõe, desenvolve e avalia atividades de ensino em diferentes espaços educativos, dentre eles a escola, dos quais participam diferentes atores com os quais precisa dialogar. Tanto os professores egressos dos cursos de licenciatura da UFJF quanto os professores formadores são vistos como atores de seu processo formativo e de seu trabalho, posição que lhes permite fazer escolhas, planejar, repensar, analisar na condução de seu trabalho. Nesse sentido, reconhecemos que o PPI avança muito na concepção de trabalho docente e na de formação inicial dos professores ao demonstrar resistência aos ataques à educação e à universidade pública atualmente vivenciados, contribuindo para a construção de uma significação que valoriza e potencializa essa profissão.

Por último, reafirmamos a coerência discursiva entre as Diretrizes de 2015 e o PPI, sobretudo quanto à compreensão da docência, do trabalho docente e da formação de professores. A partir de sua aprovação nas instâncias acadêmicas e administrativas da UFJF, o que se espera dos professores responsáveis pelos cursos de licenciatura é que sejam elaborados os Projetos Pedagógicos dos Cursos em respeito a esses dois textos prescritivos anteriores, pois, como menciona Bronckart (2009, p. 161), para que tenhamos uma melhoria da qualidade e da eficácia da formação "é urgente, hoje, (re)valorizar a profissão do professor e essa (re)valorização requer que sejam conhecidas, compreendidas e clarificadas as questões que estão em jogo, a significação e as condições de realização desse métier que é o ensino".

\section{Notas}

${ }^{1}$ Nas seções posteriores, traremos outras informações referentes à elaboração do PPI.

${ }^{2}$ No mês de abril de 2010, foi criado, no âmbito do CONGRAD - Conselho Setorial de Graduação, conforme orientação do Projeto Pedagógico das Licenciaturas então vigente (UNIVERSIDADE FEDERAL DE JUIZ DE FORA, 2006, p. 14), o Fórum das Licenciaturas. O Fórum das Licenciaturas é um espaço de discussão de questões pertinentes a esses cursos, à formação docente e ao trabalho docente. Os membros que o compõem e têm direito a voto são a coordenadora das licenciaturas da UFJF (cargo vinculado à Pró-reitoria de Graduação), os coordenadores dos cursos de licenciatura da UFJF, um representante da Faculdade de Educação, a diretora do Colégio de Aplicação João XXIII, representantes das Secretarias Municipal e Estadual de Educação e representantes dos discentes da universidade, por meio do Diretório Acadêmico. As reuniões são abertas a quem se interessar pelas discussões, pessoas que podem perguntar, opinar e solicitar esclarecimentos, no entanto, sem direito a voto.

${ }^{3}$ São eles: (I) Núcleo de formação geral; (II) Núcleo de aprofundamento e diversificação da formação docente e (III) Núcleo Profissionalizante. 


\section{Referências}

BRASIL. Parâmetros curriculares nacionais: primeiro e segundo ciclos do ensino fundamental - língua portuguesa. Brasília: MEC/SEF. 1997.

Parâmetros curriculares nacionais: terceiro e quarto ciclos do ensino fundamental - língua portuguesa. Brasília: MEC/SEF. 1998.

. Parecer CNE/CES no 492, de 3 de abril de 2001. Diretrizes curriculares para os cursos de Letras. In: BRASIL. Diretrizes Nacionais dos cursos de Arquivologia, Biblioteconomia, Ciências Sociais/Antropologia, Ciência Política e Sociologia, Comunicação Social, Filosofia, Geografia, História, Letras, Museologia e Serviço Social. Diário Oficial da União. Brasília, p. 29. 2001.

- Parecer CNE/CP 02/2015 das Diretrizes Curriculares Nacionais para a Formação Inicial e Continuada dos Profissionais do Magistério da Educação Básica. Diário Oficial da União. Brasília, 2015a.

Resolução CNE/CP no 2, de 1ㅇ de julho de 2015. Diretrizes Curriculares Nacionais para a formação em nível superior (cursos de licenciatura, cursos de formação pedagógica para graduados e cursos de segunda licenciatura) e para a formação continuada. Diário Oficial da União. Brasília, 2 de julho. 2015b.

. Base nacional comum curricular: educação é a base. Brasília: MEC, 2017.

BRONCKART, Jean-Paul. P. Atividade de linguagem, discurso e desenvolvimento humano. Campinas/SP: Mercado de Letras, 2006.

Interacionismo Sócio-discursivo: uma entrevista com Jean Paul Bronckart. Revista Virtual de Estudos da Linguagem. ReVEL. v. 4, n. 6, mar. 2006.

Restrições e liberdades textuais, inserção social e cidadania. Conferência inaugural do XIV INPLA. São Paulo, 2005.

. Posfácio. In: MACHADO, Anna Rachel; ABREU-TARDELLI, Lília Santos; CRISTOVÃO, Vera Lúcia Lopes (Orgs.). Linguagem e educação: o trabalho do professor em uma nova perspectiva. Campinas/SP: Mercado de Letras, 2009. p. 161-174.

Entrevista com o Prof. Dr. Jean Paul Bronckart. Por: CAVALCANTE, Rivadavia Porto. Revista Prolíngua, UFPB, v. 10, n. 3, nov./dez. 2015.

DOLZ, Joaquim. Posfácio. In: MACHADO, Anna Rachel; ABREU-TARDELLI, Lília Santos; CRISTOVÃO, Vera Lúcia Lopes (Orgs.). Linguagem e educação: o ensino e a aprendizagem de gêneros textuais. Campinas, São Paulo: Mercado de Letras, 2009. p. 165-172.

GARCIA-REIS, Andreia Rezende. Práticas de linguagem na formação dos professores de Língua Portuguesa: uma perspectiva de análise do Projeto Pedagógico do curso de Letras. Revista Veredas, Juiz de Fora, MG, v. 21, jan./jun. 2017. 
; SILVA, Andressa Barcellos Correia. A formação inicial em Letras e o desenvolvimento de capacidades linguísticas por meio dos gêneros textuais. In: CADILHE, Alexandre; GARCIA-REIS, Andreia Rezende; MAGALHÃES, Tânia Guedes. Formação docente: linguagens, práticas e perspectivas. Campinas/SP: Pontes, 2018. p. 63-84.

GATTI, Bernardete Angelina. Educação, escola e formação de professores: políticas e impasses. Educação em Revista, Curitiba, n. 50, p. 51-67, dez. 2013.

Formação de professores no Brasil: características e problemas. Educação \& Sociedade, São Paulo, v. 31, n. 113, p. 1355-1379, dez. 2010.

MACHADO, Anna Rachel. Por uma concepção ampliada do trabalho do professor. In: GUIMARÃES, Ana Maria de Mattos; MACHADO; Anna Rachel; COUTINHO, Antonia (Orgs.). 0 interacionismo sociodiscursivo: questões epistemológicas e metodológicas. Campinas/SP: Mercado de Letras, 2007. p. 77-97.

; CRISTOVÃO, Vera Lúcia Lopes. Representações sobre o professor e seu trabalho em proposta institucional brasileira para a formação docente. In: MACHADO, Anna Rachel; ABREU-TARDELLI, Lília Santos; CRISTOVÃO, Vera Lúcia Lopes (Orgs.). Linguagem e educação: o trabalho do professor em uma nova perspectiva. Campinas/SP: Mercado de Letras, 2009. p. 117-136.

; ABREU-TARDELLI, Lília Santos. Textos prescritivos da educação presencial e a distância: fonte primeira do estresse do professor? In: MACHADO, A. R. e colaboradores. ABREU-TARDELLI, Lília Santos; CRISTOVÃO, Vera Lúcia Lopes (Orgs.). Linguagem e educação: o trabalho do professor em uma nova perspectiva. Campinas, SP: Mercado de Letras, 2009. p. 101-116.

; LOUSADA, Eliane Gouvêa. As pesquisas do grupo ALTER-LAEL para a análise do trabalho educacional. Cadernos de Psicologia Social do Trabalho, São Paulo, v. 16, n. especial 1, 2013, p. 35-46.

. Colaboração e crítica: possíveis ações do linguista na atividade educacional. In: ABREU-TARDELLI, Lília Santos; CRISTÓVÃO, Vera Lúcia Lopes (Orgs.). Linguagem e educação: o ensino e a aprendizagem de gêneros textuais. Campinas, SP: Mercado de Letras, 2009. p. 43-70.

NÓVOA, António. Firmar a posição como professor, afirmar a profissão docente. Cadernos de Pesquisa, São Paulo, v. 47, n. 166, p. 1106-1133, 2017. Disponível em: http://www.scielo.br/pdf/cp/v47n166/19805314-cp-47-166-1106.pdf. Acesso em: 20 out. 2018.

PEREIRA, Regina Celi Mendes; MEDRADO, Betânia Passos; REICHMANN, Carla Lynn. Letramentos e práticas formativas: pesquisas tecidas nas entrelinhas do ISD. João Pessoa: Editora da UFPB, 2015.

UNIVERSIDADE FEDERAL DE JUIZ DE FORA. Projeto Pedagógico Institucional das Licenciaturas da Universidade Federal de Juiz de Fora. Versão preliminar. 05/2018. 